\title{
BMJ Open Ethnic differences in the progression of chronic kidney disease and risk of death in a UK diabetic population: an observational cohort study
}

\author{
Rohini Mathur, ${ }^{1}$ Gavin Dreyer, ${ }^{2}$ Magdi M Yaqoob, ${ }^{2}$ Sally A Hull ${ }^{1}$
}

To cite: Mathur R, Dreyer G, Yaqoob MM, et al. Ethnic differences in the progression of chronic kidney disease and risk of death in a UK diabetic population: an observational cohort study. BMJ Open 2018;8:e020145. doi:10.1136/ bmjopen-2017-020145

- Prepublication history and additional material for this paper are available online. To view these files, please visit the journal online (http://dx.doi org/10.1136/bmjopen-2017020145).

Received 17 October 2017 Revised 5 February 2018 Accepted 7 February 2018
Check for updates

${ }^{1}$ Centre for Primary Care and Public Health, Queen Mary University of London, London, UK

${ }^{2}$ Department of Nephrology, Barts Health NHS trust, London, UK

Correspondence to

Dr. Sally A Hull;

s.a.hull@qmul.ac.uk

\section{ABSTRACT}

Objective To determine ethnic differences in the progression of chronic kidney disease (CKD) and risk of end-stage renal failure (ESRF) and death in adults with type 2 diabetes mellitus (T2DM), and to identify predictors of rapid renal decline.

Design Observational community-based cohort study undertaken from 2006 to 2016 with nested case-control study.

Setting 135 inner London primary care practices contributing to the east London Database.

Participants General practice-registered adults aged 25-85 years with established T2DM and CKD at baseline. Outcomes The annual rate of renal decline was compared between white, south Asian and black groups, and stratified by proteinuria and raised blood pressure (BP) at baseline. Predictors of rapid renal decline were identified in a nested case-control study. Cox proportional hazards regression was used to determine ethnic differences in the risk of ESRF and death.

Results Age-sex adjusted annual decline was greatest in the Bangladeshi population. There was stepwise increase in the rate of decline when stratifying the cohort by baseline proteinuria and BP control, with south Asian groups being most sensitive to the combined effect of proteinuria and raised BP after accounting for key confounders. The odds of rapid renal decline were increased for individuals of Bangladeshi, African and Caribbean ethnicity, those with hypertension, proteinuria, cardiovascular disease and with increasing duration of diabetes. Rapid progression was more frequent in younger age groups. Risk of developing ESRF was highest in the black group compared with the white group (HR 1.88, $95 \% \mathrm{Cl} 1.11$ to 3.19). Risk of death from any cause was $29 \%$ lower in the south Asian group compared with the white group (HR $0.71,95 \% \mathrm{Cl} 0.56$ to 0.91 ).

Conclusions Proteinuria and hypertension trigger accelerated estimated glomerular filtration rate decline differentially by ethnicity. Active monitoring of younger adults, who have greater odds of rapid progression and the most to gain from interventions, is essential.

\section{INTRODUCTION}

Chronic kidney disease (CKD) is a common complication of diabetes mellitus. In the $\mathrm{UK}$, it is estimated that up to $30 \%$ of patients

\section{Strengths and limitations of this study}

- Completeness of ethnicity recording was over $90 \%$ in the study population, allowing a rare opportunity to conduct an in-depth exploration of differences between both high-level ethnic groups and constituent subgroups.

- Study patients comprised $98 \%$ of the eligible general practice-registered population, came from a single contiguous geographical area, and thus were representative of the wider east London population.

- The median follow-up of 9 years was higher than for database studies of general populations, as individuals with established type 2 diabetes mellitus tend to be older and less geographically mobile than younger population groups.

- As with any observational database study using routinely collected clinical data, some individuals had missing or erroneous data for the variables of interest, with patterns of missing-ness likely related to duration and severity of disease.

- Our inability to capture predictors not available in routine primary care data such as over-the-counter medications, hospital admissions, patient frailty and biomarkers may have resulted in unmeasured residual confounding.

with type 2 diabetes mellitus (T2DM) have CKD stages 3-5. ${ }^{1}$ Ethnic minority groups are known to have a higher prevalence of T2DM and end-stage renal failure (ESRF) compared with the white majority population. ${ }^{23}$ Whether this excess of ESRF is a result of faster progression of CKD in ethnic minority groups remains poorly understood. ${ }^{4}$ In the USA, higher rates of decline among black groups have been observed which may be related to social deprivation or differences in access to healthcare ${ }^{56}$ In the UK and the Netherlands, where access to healthcare is universal, studies have reported both faster decline in non-white groups ${ }^{7-10}$ and equivalent decline between ethnic groups. ${ }^{11} 12$ 
Hypertension and proteinuria are known to accelerate the progression of renal decline $\mathrm{e}^{13-15}$; whether these factors and other predictors such as cardiovascular disease, smoking status, body mass index (BMI) and medication use act differentially between ethnic groups has yet to be explored. The identification of modifiable risk factors for deterioration in renal function is important for optimal review and management in primary care and the effective use of specialist services. This is of particular importance as the UK population ages and becomes more ethnically diverse.

The aim of this study was to establish the role of ethnicity alongside other major risk factors in the progression of CKD in people with T2DM managed in community settings. Secondary aims included identifying predictors of rapid renal decline $\left(>5 \mathrm{~mL} / \mathrm{min} / 1.73 \mathrm{~m}^{2}\right.$ of estimated glomerular filtration rate (eGFR) a year) and ethnic differences in the risk of developing ESRF and death.

\section{MATERIALS AND METHODS \\ Setting and population}

The study was set in the three geographically contiguous East London clinical commissioning groups (CCGs) of Newham, Tower Hamlets and City and Hackney. Patients were registered with 134 general practices (GPs), with a combined GP-registered population of 912668 patients in 2011 (the midpoint of this study). This practice data covered more than $98 \%$ of the GP-registered population in the three CCGs. According to the 2011 UK census, $58 \%$ of the population in the study area were identified as being of non-white ethnic origin. ${ }^{16}$ Practice computer databases were interrogated using EMIS Web software. ${ }^{17}$ Demographic and clinical data were obtained for the period 2006-2016 for all adult patients with a diagnostic Read code for T2DM. Patients were included in the study if they had an eGFR of between 15 and $60 \mathrm{~mL} / \mathrm{min} / 1.73 \mathrm{~m}^{2}$ on two or more readings at least 3 months apart following their initial T2DM diagnosis, could provide three or more years of follow-up data and were between 25 and 85 years of age at entry to the study. Patients with diagnostic Read codes for haemodialysis or peritoneal dialysis, or ESRF prior to entry to the study were excluded (see online supplementary figure 1 for population inclusion flow chart). All data were anonymised and managed according to UK National Health Service information governance requirements.

\section{Study design}

This was an observational cohort study using prospectively collected electronic primary care data from the East London Database. ${ }^{18}$ CKD onset (stage 3 or below) was defined as the date of the latest of the first two eGFR readings between 15 and $60 \mathrm{~mL} / \mathrm{min} / 1.73 \mathrm{~m}^{2}$ recorded at least 3 months apart. All eGFR values were calculated from recorded creatinine values in the patient record using the four variable modification of diet in renal disease (MDRD) equation, which adjusts for gender and black ethnicity, and is used widely in UK primary and secondary care. ${ }^{19}$ Values recorded between 2003 and 2005 were used to identify CKD onset prior to the start of the study period while values recorded from 2006 to 2016 were used to identify CKD onset during the study period. For patients with CKD onset before the start of the study period, follow-up commenced on 1 April 2006. For patients who developed CKD after 1 April 2006, follow-up commenced on the date of CKD onset. For the analysis of eGFR decline over time and risk of ESRF, the follow-up period ended at the earliest of: dialysis commencement, diagnosis of ESRF, death, deregistering from the practice or 1 April 2016. For the analysis of risk of death, the follow-up period ended at the earliest of death, de-registering from the practice or 1 April 2016.

\section{Exposures}

T2DM diagnoses were identified via the $\mathrm{C10F} \%$ Read code on the electronic health record. Self-reported ethnicity recorded at the practice during registration or routine consultation was identified via the $9 \mathrm{i} \%$ and $9 \mathrm{~S} \%$ Read codes. Read codes for ethnicity were collapsed into the 16 categories of the UK 2001 census. For this study, ethnicity was considered in two ways; first in the three high-level categories of white, south Asian and black, and second, with the non-white groups further broken down into Indian, Pakistani, Bangladeshi, African and Caribbean. Individuals of mixed ethnicity were grouped with their parent ethnic minority. For example, individuals who had classified themselves as mixed white and African were classed as African for the purposes of this study. Patients with other, unknown or missing ethnicity were not included in the analysis. The Townsend score (derived from census variables and linked to patient place of residence) was used as a measure of social deprivation. ${ }^{20}$

\section{Outcomes}

For the analysis of ethnic differences in progression towards ESRF, the outcome of annual change in eGFR was determined by calculating a single eGFR value for each year of follow-up, based on the average of all individual eGFR values recorded in that year for each patient. If eGFR was missing in any 1 year, the average eGFR value from the previous year was brought forward.

For the nested case-control study identifying predictors of rapid renal decline, cases and controls were defined according to their overall eGFR progression which was calculated using the equation (baseline eGFR-final eGFR)/total years of follow-up), with baseline and final eGFR referring to the annualised average eGFR in the first and last years of follow-up.

Individuals in or above the 95th percentile for overall eGFR progression were considered rapid progressors. Within our study cohort, this equated to an average annual eGFR loss of $\geq 5 \mathrm{~mL} / \mathrm{min} / 1.73 \mathrm{~m}^{2}$ (online supplementary table 1). ESRF was identified using Read codes for dialysis and ESRF, with date of onset defined as the earliest entry of either code on 
the patient record. Death was identified using the date of patient d-registration, where the patients' registration status was coded as 'deceased'.

\section{Covariates}

Covariate data were extracted on 1st April of each study year between 2006 and 2016, and defined as the latest recorded value in the preceding 12 months. Covariates considered for analysis included age, gender, Index of Multiple Deprivation score, systolic blood pressure (SBP), glycated haemoglobin (HbAlc), proteinuria, smoking status, BMI, diagnosed cardiovascular disease (ischaemic heart disease, heart failure, stroke, peripheral vascular disease) and any prescription of ACE inhibitors and angiotensin receptor blockers (ARBs). Proteinuria was considered 'positive' if the patient had a protein:creatinine ratio $\geq 15 \mathrm{mg} / \mathrm{mmol}$, an albumin:creatinine ratio value $\geq 2.5 \mathrm{mg} / \mathrm{mmol}$ for men, or $\geq 3.5 \mathrm{mg} / \mathrm{mmol}$ for women, or a urine dipstick result $\geq$ ' $1+$ '. Raised blood pressure was considered to be an SBP reading of $>130 \mathrm{~mm}$ $\mathrm{Hg}$. Smoking status was dichotomised into current smoker and current non-smoker (see online supplementary table 2 for code lists).

\section{Statistical analysis}

All statistical analyses were performed using Stata V.14. For the analysis of ethnic differences in the annual rate of eGFR progression towards ESRF, annual change in eGFR was determined using a multilevel linear regression panel with continuous eGFR as the outcome and years of follow-up as the main predictor, with multiple observations nested within patients who were further nested within practices. The annual change in eGFR was calculated for the cohort as a whole and separately for each ethnic group in turn. All analyses were stratified by the presence of proteinuria and/or raised SBP at baseline and adjusted for both a priori variables as measured at baseline (age, sex, eGFR, ACE/ARB) and baseline variables found to be significantly associated with eGFR in univariable analysis (HbAlc, cardiovascular disease (CVD) and duration of diabetes).

Predictors of rapid renal decline towards ESRF were determined using a nested case-control study. Cases were defined as individuals who had an annual average eGFR decline of $\geq 5 \mathrm{~mL} / \mathrm{min} / 1.73 \mathrm{~m}^{2}$ per year based on the difference between their baseline and final eGFR values. Controls were defined as all individuals whose average annual rate of decline was below $5 \mathrm{~mL} / \mathrm{min} / 1.73 \mathrm{~m}^{2}$ per year. Logistic regression was used to determine the odds of having experienced rapid eGFR decline. The model was adjusted for a priori variables as measured at baseline (age, gender, ethnic group, raised SBP, proteinuria, duration of diabetes, eGFR and ACE/ARB prescription) and baseline CVD, the only additional variable found to be significantly associated with rapid progression in the univariable analysis.

Cox proportional hazards regression modelling was used to determine ethnic differences in the risk of ESRF and risk of death. Both models were adjusted for a priori variables (age at baseline, gender, eGFR, ACE/ARB prescription, smoking status, SBP value, proteinuria and duration of diabetes at baseline) and variables found to be significantly associated with ESRF and death in the univariable analysis (BMI, HbAlc, CVD, deprivation). The analysis for risk of death was additionally adjusted for dialysis/ESRF. Age, diabetes duration, ethnicity, gender and deprivation were treated as time-constant variables. All other variables were time-updated in each year of follow-up to account for temporal changes in values, incident diagnoses or initiation of treatment during follow-up. For the risk of ESRF, a competing risks framework was employed as death may have competed with ESRF, the outcome of interest. For the risk of death, a standard Cox regression model was used as ESRF does not preclude the outcome of interest occurring.

\section{RESULTS}

From 120591 adults with T2DM identified in the East London practice database between 2006 and 2016, 6274 individuals of white, south Asian or black African/Caribbean ethnicity with CKD, aged 25-84 years and free from ESRF/ dialysis at baseline were eligible for inclusion in the study (online supplementary figure 1). Mean follow-up time was 9.0 years. Both south Asian and black groups had a longer duration of diabetes and a higher HbA1c value at baseline compared with the white group. Baseline eGFR was similar between ethnic groups; prevalence of proteinuria and hypertension at baseline was highest in the black African/Caribbean group and lowest in the south Asian group (table 1).

\section{Ethnic differences in eGFR decline}

The annual age-sex-adjusted rate of eGFR decline for the whole cohort was $-0.86 \mathrm{~mL} / \mathrm{min} / 1.73 \mathrm{~m}^{2}$ (95\% CI -0.89 to -0.83$)$. When broken down by ethnic group, decline was significantly faster in the south Asian group relative to the white group and significantly slower in the black group. When broken down further by ethnic subgroup, annual change in eGFR was significantly faster in the Bangladeshi group compared with the Indian group, and comparable between African and Caribbean groups (figure 1).

\section{Stratification by risk factor control}

Stratification by baseline blood pressure and proteinuria status showed that the rate of eGFR decline was faster in those with proteinuria alone compared with hypertension alone, and fastest overall for individuals with both. South Asian patients were found to be most sensitive to the combined effect of proteinuria and hypertension after accounting for key confounders $\left(-1.94 \mathrm{~mL} / \mathrm{min} / 1.73 \mathrm{~m}^{2}\right.$, $95 \%$ CI -2.15 to -1.73 ) (table 2 ). Further stratification by ethnic subgroup revealed significant heterogeneity in the effects of hypertension and proteinuria on eGFR decline, with no clear patterns evident (online supplementary material table 2). 
Table 1 Baseline characteristics and outcome measures for the study population

\begin{tabular}{|c|c|c|c|c|c|c|}
\hline Baseline characteristics & $\begin{array}{l}\mathrm{N} \text { with } \\
\text { complete } \\
\text { data }\end{array}$ & White & South Asian & Black & $\begin{array}{l}P \text { values, } \\
\text { SA vs white }\end{array}$ & $\begin{array}{l}\text { P values, } \\
\text { black vs } \\
\text { white }\end{array}$ \\
\hline N & 6274 & 2447 & 2732 & 1095 & & \\
\hline Mean years of follow-up (SD) & 6274 & $9.2(2.2)$ & $8.8(2.3)$ & $9.0(2.3)$ & $<0.001$ & $<0.001$ \\
\hline \multicolumn{7}{|l|}{ Diabetes characteristics } \\
\hline $\begin{array}{l}\text { Diabetes duration at baseline, } \\
\text { mean (SD) }\end{array}$ & 6274 & $7.8(6.7)$ & $9.9(7.7)$ & $10.8(8.3)$ & $<0.001$ & $<0.001$ \\
\hline \multicolumn{7}{|l|}{ Baseline measures } \\
\hline Men, \% & 6274 & 41.9 & 48.4 & 42.5 & $<0.001$ & 0.73 \\
\hline Mean age (SD) & 6274 & $69.5(9.3)$ & $65.5(9.9)$ & $67.8(10.0)$ & $<0.001$ & $<0.001$ \\
\hline Mean systolic blood pressure (SD) & 6022 & $135.3(17.1)$ & $133.2(17.8)$ & $138.8(18.2)$ & $<0.001$ & $<0.001$ \\
\hline Mean diastolic blood pressure (SD) & 6022 & $74.3(10.0)$ & $73.9(10.0)$ & $76.5(10.2)$ & 0.312 & $<0.001$ \\
\hline Mean HbA1c (IFCC aligned) (SD) & 5346 & $58.8(16.4)$ & $63.1(17.4)$ & $63.0(20.7)$ & $<0.001$ & $<0.001$ \\
\hline Current smokers, $\%$ & 5882 & 16.2 & 12.9 & 7.0 & 0.001 & $<0.001$ \\
\hline Positive proteinuria, $\%$ & 4627 & 33.2 & 30.0 & 36.6 & $<0.001$ & 0.515 \\
\hline \multicolumn{7}{|l|}{ CKD stage at baseline (based on eGFR) } \\
\hline Mean eGFR, mL/min/1.73 m² (SD) & 6274 & $51.2(8.2)$ & $51.6(8.3)$ & $51.8(8.1)$ & 0.088 & 0.051 \\
\hline Stage $3 a$ & & 81.5 & 82.9 & 83.6 & 0.16 & 0.129 \\
\hline Stage 3b & & 15.7 & 13.9 & 13.2 & & \\
\hline Stage 4 & & 2.8 & 3.2 & 3.2 & & \\
\hline \multicolumn{7}{|c|}{ Baseline medication use (ever prescribed in the 12 months preceding) } \\
\hline ACE/ARB & 6274 & 81.7 & 82.2 & 85.3 & 0.686 & 0.009 \\
\hline \multicolumn{7}{|l|}{ Baseline comorbidities } \\
\hline $\begin{array}{l}\text { Coded hypertension or SBP } \\
>130 \mathrm{~mm} \mathrm{Hg}, \%\end{array}$ & 6274 & 88.4 & 75.0 & 94.8 & $<0.001$ & $<0.001$ \\
\hline $\begin{array}{l}\text { CVD (CHD, stroke, heart failure, } \\
\text { PVD), \% }\end{array}$ & 6274 & 42.8 & 40.0 & 30.2 & 0.045 & $<0.001$ \\
\hline \multicolumn{7}{|l|}{ Outcome measures } \\
\hline Rapid decline (>5 mm/mol), \% & 6274 & 3.4 & 4.9 & 6.8 & 0.006 & $<0.001$ \\
\hline ESRF/dialysis, \% & 6274 & 2.3 & 4.3 & 4.7 & $<0.001$ & $<0.001$ \\
\hline Death, \% & 6274 & 18.8 & 12.2 & 12.7 & $<0.001$ & $<0.001$ \\
\hline
\end{tabular}

Baseline date is defined as the latest date of CKD onset or 1 April 2006.

ARB, angiotensin receptor blocker; CHD, coronary heart disease; CKD, chronic kidney disease; CVD, cardiovascular disease; eGFR, estimated glomerular filtration rate; ESRF, end-stage renal failure; HbA1c, glycated haemoglobin; IFCC, International Federation of Clinical Chemistry; PVD, peripheral vascular disease; SA, South Asian; SBP, systolic blood pressure.

\section{Predictors of rapid eGFR decline}

After stratifying the study population by overall eGFR decline, $3.4 \%$ of white patients, $4.9 \%$ of South Asian patients and $6.8 \%$ of black patients were identified as rapid progressors (crude annual decline in eGFR of $\geq 5 \mathrm{~mL} / \mathrm{min} / 1.73 \mathrm{~m}^{2}$ ) (table 3 and figure 2 ). After adjustment for known confounders, the odds of having rapid progression were found significantly raised in African, Caribbean and Bangladeshi groups relative to the white group, with the OR largest for the African group (OR 2.53, 95\% CI 1.63 to 3.92). The odds of rapid decline were doubled for patients aged $25-54$ years (OR 1.96 , CI95\% 1.34 to 2.85 ) and raised by $38 \%$ for those aged 55-64 years (OR 1.38, CI95\% 0.99 to 1.92) relative to those aged 65-74 years. Both raised blood pressure and proteinuria were independently associated with increased odds of being a rapid progressor, as was the presence of CVD at baseline. The odds of rapid progression increased with each category of diabetes duration, relative to those with the shortest duration (table 4).

\section{Ethnic differences in the risk of ESRF}

The risk of ESRF was more than doubled in the black groups relative to the white group in a fully adjusted analysis which also took account of the competing risk of death (HR 2.23, 95\% CI 1.25 to 2.98). When broken down further by ethnic subgroup, the increased risk was apparent in both the African and Caribbean groups relative to the white group (African HR 2.29, 95\% CI 1.12 to 4.64; Caribbean HR 2.20, 95\% CI 1.14 to 4.27 ) (table 5). 


\section{Annual change in eGFR ( $\mathrm{ml} / \mathrm{min} / 1.73 \mathrm{~m} 2)$}

\section{Age-sex adjusted}

Ethnic group

Coeff $(95 \% \mathrm{Cl})$

\begin{tabular}{|c|c|c|}
\hline Whole population & $\bullet$ & $-0.68(-0.70,-0.66)$ \\
\hline \multicolumn{3}{|l|}{ Main ethnic groups } \\
\hline White & $\bullet$ & $-0.64(-0.68,-0.60)$ \\
\hline South Asian & $\bullet$ & $-0.77(-0.81,-0.74)$ \\
\hline Black & $\rightarrow$ & $-0.55(-0.61,-0.48)$ \\
\hline \multicolumn{3}{|l|}{ Ethnic sub groups } \\
\hline Indian & $\rightarrow$ & $-0.69(-0.75,-0.63)$ \\
\hline Pakistani & $\rightarrow$ & $-0.83(-0.92,-0.75)$ \\
\hline Bangladeshi & $\rightarrow$ & $-0.85(-0.90,-0.79)$ \\
\hline African & $\longrightarrow$ & $-0.64(-0.76,-0.51)$ \\
\hline Caribbean & $\rightarrow$ & $-0.51(-0.58,-0.44)$ \\
\hline
\end{tabular}

Figure 1 Age-sex-adjusted eGFR progression rate by ethnic group. eGFR, estimated glomerular filtration rate .

\section{Ethnic differences in the risk of death}

After accounting for age, sex, deprivation, HbAlc, BMI, smoking status, eGFR, proteinuria, CVD, ACE/ARB prescriptions, ESRF and diabetes duration, risk of death was significantly reduced in the South Asian population relative to the white group (HR 0.71, 95\% CI 0.56 to 0.91 ), with decreased risk driven entirely by the Bangladeshi population (HR $0.63,95 \%$ CI 0.46 to 0.86 ). No differences in the risk of death between white and black groups was found (table 6).

\section{DISCUSSION}

This observational study of over 6000 primary care patients followed for an average of 9 years represents the largest UK-based study examining ethnic differences in

Table 2 Fully adjusted eGFR progression rate stratified by baseline blood pressure and proteinuria status for the main ethnic groups

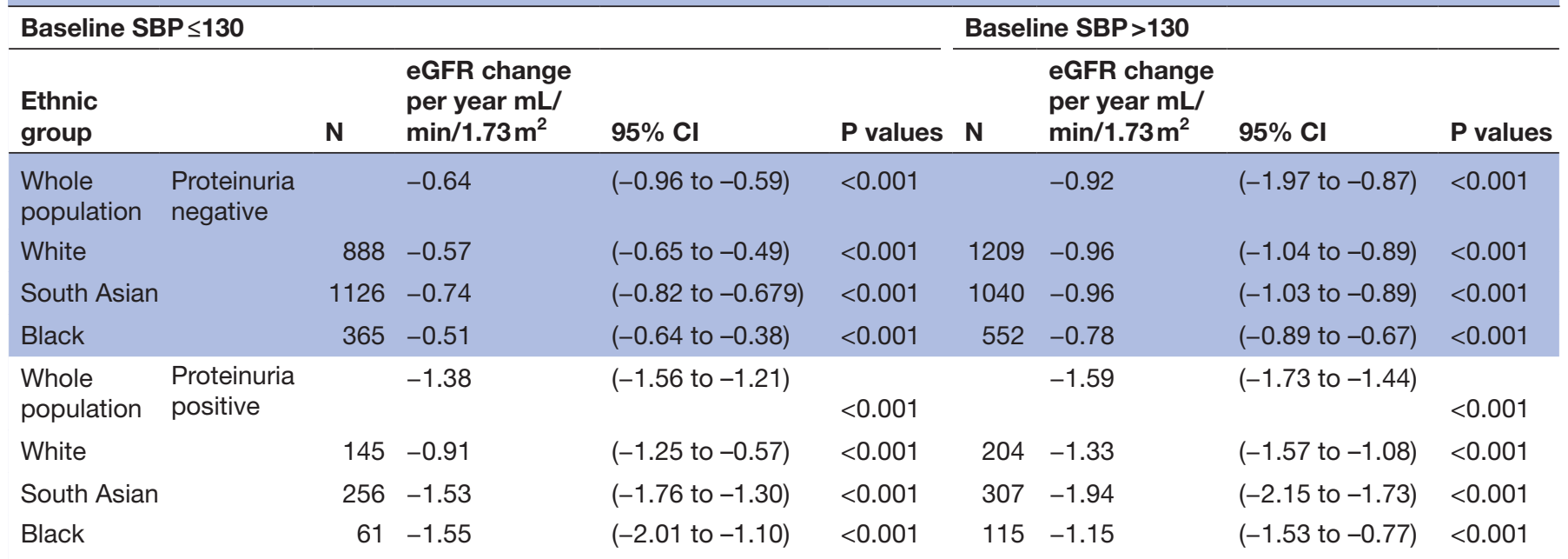

Model adjusted for age, sex and baseline measures of HbA1c, eGFR, CVD, ACE/ARB and diabetes duration.

ARB, angiotensin receptor blocker; CVD, cardiovascular disease; eGFR, estimated glomerular filtration rate; HbA1c, glycated haemoglobin; SBP, systolic blood pressure. 
Table 3 Annual change in estimated glomerular filtration rate (eGFR) by ethnic group based on overall progression (\%)

\begin{tabular}{lllllllllll}
\hline & eGFR change & White & South Asian & Indian & Pakistani & Bangladeshi & Black & African Caribbean & Total \\
\hline & Increase/stable & 41.7 & 39.4 & 37.5 & 35 & 41.6 & 42.6 & 45.8 & 41.1 & 40.8 \\
Controls & $1-4 \mathrm{~mL} / \mathrm{min} / 1.73 \mathrm{~m}^{2}$ decrease & 55.0 & 55.7 & 59 & 61.4 & 52 & 50.6 & 44.9 & 55.3 & 54.6 \\
Cases & $5-21 \mathrm{~mL} / \mathrm{min} / 1.73 \mathrm{~m}^{2}$ decrease & 3.4 & 4.9 & 3.5 & 3.6 & 6.4 & 6.8 & 9.3 & 5.6 & 4.7 \\
\hline
\end{tabular}

progression of CKD in a community-managed diabetic cohort. We identified an overall annual decline of $-0.86 \mathrm{~mL} / \mathrm{min}$. We showed that while South Asian patients, particularly of Bangladeshi ethnicity, had the greatest annual loss of eGFR and significantly reduced risk of death relative to white groups, black groups were most at risk of rapid CKD progression and had the highest risk of developing ESRF.

This study is consistent with other studies showing significantly faster renal progression and lower risk of death in South Asian groups compared with white groups. A Canadian study of 3444 patients referred to nephrology clinics with CKD found that South Asian groups had a higher risk of progressing to ESRF than white groups (HR 1.35, $\mathrm{p}<0.05)$ and a lower risk of all-cause mortality (HR $0.69, \mathrm{p}<0.05$ ). However, in contrast to our cohort, this study was not restricted to patients with established T2DM, was not a community-managed cohort and did not include individuals of black ethnicity. ${ }^{21}$

The average annual rate of renal decline was found to be equivalent between white, African and Caribbean populations in our study, even after adjustment for key confounders and stratification by proteinuria and raised blood pressure status. Equivalence in renal decline and risk of death between black and white populations has been reported recently in the USA. ${ }^{22} 23$ Ethnic differences in CKD progression and outcomes may be attenuated in settings where patients of different ethnic groups have equal access to care and equitable management of risk factors such as blood pressure, CVD risk and proteinuria.
In countries such as the UK, Canada and the Netherlands, access to primary healthcare is free at the point of need, a key factor in reducing inequalities in health outcomes. A recent meta-regression of 1.1 million adults from 45 cohorts found that the risk of all-cause mortality, ESRF and low eGFR was comparable between Asian, white and black ethnic groups though this study included a number of large non-diabetic cohorts which may account for the lack of difference between white and Asian populations. ${ }^{24}$

Though average annual decline was found to be comparable between white and black Caribbean ethnic groups, the odds of having rapid eGFR progression was found significantly raised for black groups relative to white. This apparent inconsistency may be explained by the fact that a single measure of average annual decline in each ethnic group may mask heterogeneity in eGFR trajectory. Over the study follow-up period, patients either lost eGFR, remained at a stable eGFR or gained eGFR. In our study population, the proportion of patients belonging to each of these categories varied by ethnic group. Black patient were over-represented in both the increasing eGFR category and the rapid decline category relative to the white and South Asian groups (figure 2).

Bangladeshi ethnicity, hypertension, proteinuria, diabetes duration and CVD were also independently associated with the increased odds of having rapid renal decline, after mutual adjustment for all risk factors captured in the study. For diabetes duration, a doseresponse relationship was apparent. Significantly, we noted an inverse relationship between age and rapid

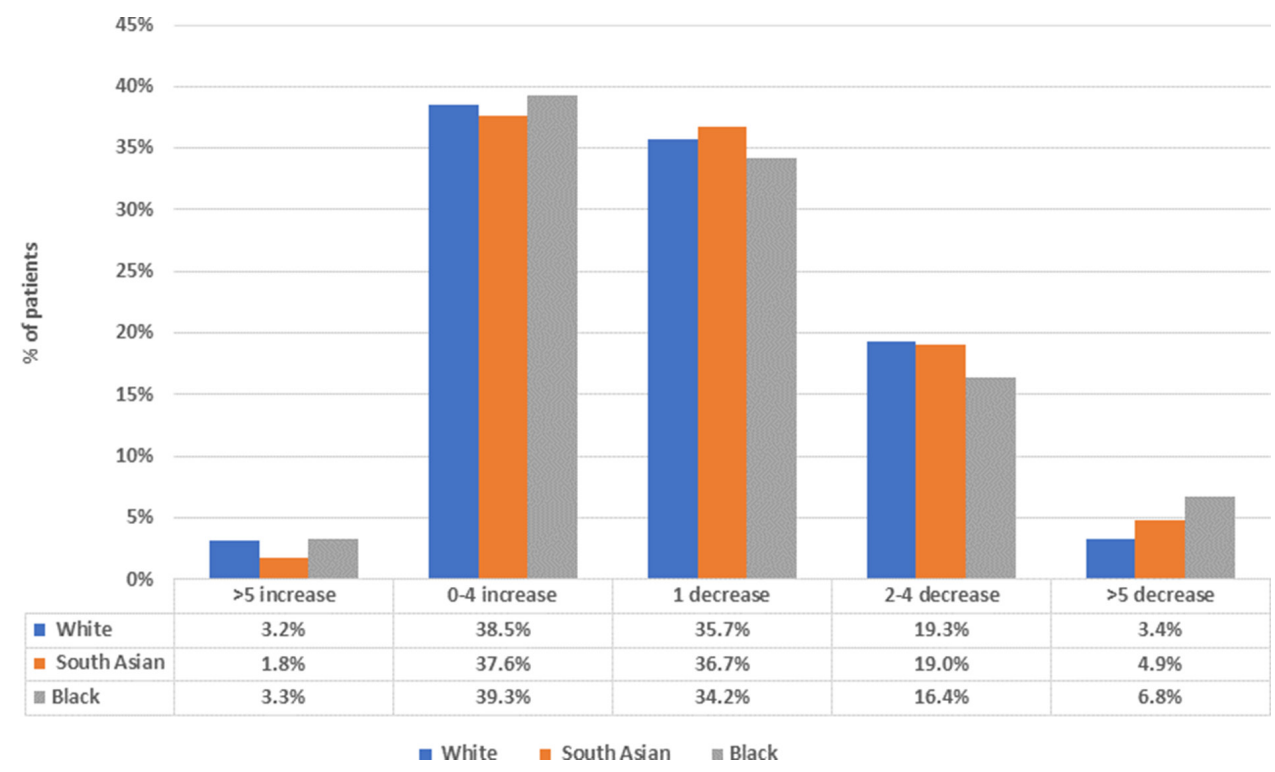

Figure 2 Crude annual change in estimated glomerular filtration rate based on overall progression $\left(\mathrm{mL} / \mathrm{min} / 1.73 \mathrm{~m}^{2}\right)$. 
Table 4 Multivariable analysis of risk factors for rapid progression ( $25 \mathrm{~mL} / \mathrm{min} /$ year)

\begin{tabular}{|c|c|c|c|c|c|c|}
\hline & $\mathbf{N}$ & Rapid & Per cent & $\mathrm{aOR}^{*}$ & $95 \% \mathrm{Cl}$ & $P$ values \\
\hline \multicolumn{7}{|l|}{ Ethnic group } \\
\hline White (reference) & 2446 & 82 & 3 & 1.00 & - & \\
\hline South Asian & 2729 & 133 & 5 & 1.28 & (0.96 to 1.71$)$ & 0.098 \\
\hline Indian & 822 & 29 & 4 & 0.92 & (0.60 to 1.44$)$ & 0.753 \\
\hline Pakistani & 414 & 15 & 4 & 0.95 & $(0.55$, to 1.71$)$ & 0.905 \\
\hline Bangladeshi & 1242 & 80 & 6 & 1.70 & (1.23 to 2.38$)$ & 0.001 \\
\hline Black & 1093 & 74 & 7 & 1.93 & (1.39 to 2.70 ) & $<0.001$ \\
\hline African & 356 & 33 & 9 & 2.53 & (1.64 to 3.93 ) & $<0.001$ \\
\hline Caribbean & 737 & 41 & 6 & 1.63 & (1.10 to 2.40$)$ & 0.016 \\
\hline \multicolumn{7}{|l|}{ Age at baseline } \\
\hline $25-54$ & 723 & 50 & 7 & 1.96 & (1.34 to 2.85 ) & $<0.001$ \\
\hline $55-64$ & 1405 & 67 & 5 & 1.38 & (0.99 to 1.92 ) & 0.057 \\
\hline 65-74 (reference) & 2497 & 95 & 4 & 1.00 & - & \\
\hline $75-85$ & 1643 & 77 & 5 & 1.30 & (0.95 to 1.79 ) & 0.103 \\
\hline \multicolumn{7}{|l|}{ Gender } \\
\hline Female (reference) & 3459 & 135 & 4 & 1.00 & - & \\
\hline Male & 2809 & 154 & 5 & 1.26 & (0.98 to 1.61$)$ & 0.072 \\
\hline \multicolumn{7}{|l|}{ Baseline SBP } \\
\hline $\begin{array}{l}<130 \mathrm{~mm} \mathrm{Hg} \\
\text { (reference) }\end{array}$ & 2841 & 108 & 4 & 1.00 & - & \\
\hline$\geq 130 \mathrm{~mm} \mathrm{Hg}$ & 3427 & 181 & 5 & 1.52 & (1.18 to 1.96$)$ & 0.001 \\
\hline \multicolumn{7}{|l|}{ Baseline proteinuria } \\
\hline No (reference) & 5180 & 204 & 4 & 1.00 & - & \\
\hline Yes & 1088 & 85 & 8 & 1.74 & (1.32 to 2.30$)$ & $<0.001$ \\
\hline \multicolumn{7}{|l|}{ Duration of diabetes } \\
\hline $0-4$ years (reference) & 2299 & 67 & 3 & 1.00 & - & \\
\hline $5-9$ years & 1531 & 75 & 5 & 1.64 & (1.17 to 2.32 ) & 0.005 \\
\hline 10-19years & 1820 & 105 & 6 & 1.89 & (1.36 to 2.61$)$ & $<0.001$ \\
\hline $20+$ years & 618 & 42 & 7 & 1.99 & (1.30 to 3.04 ) & 0.002 \\
\hline Baseline eGFR & & & & 1.00 & (0.99 to 1.02 ) & 0.829 \\
\hline \multicolumn{7}{|l|}{ ACE/ARB at baseline } \\
\hline No (reference) & 1176 & 50 & 4 & 1.00 & - & \\
\hline Yes & 5092 & 239 & 5 & 0.89 & (0.64 to 1.25$)$ & 0.513 \\
\hline \multicolumn{7}{|l|}{ CVD at baseline } \\
\hline No (reference) & 3957 & 153 & 4 & 1.00 & - & \\
\hline Yes & 2311 & 136 & 6 & 1.45 & (1.13 to 1.87 ) & 0.004 \\
\hline
\end{tabular}

${ }^{*}$ All variables are mutually adjusted for one another.

aOR, adjusted OR; ARB, angiotensin receptor blocker; CVD, cardiovascular disease; eGFR, estimated glomerular filtration rate; SBP, systolic blood pressure.

progression, highlighting the importance of regular scrutiny and active management for those individuals who develop CKD prior to the age of 65 years.

\section{Strengths}

The recording of ethnicity was incentivised across the UK from 2006 to 2016, resulting in over $90 \%$ completeness of ethnicity recording for patients with T2DM in our electronic health database during the study period. This allowed us a rare opportunity to conduct an in-depth exploration of differences in both high-level ethnic groups and constituent subgroups. Patients contributing to the study were registered with primary care practices in a single contiguous geographical area which were unselected, and hence representative of East London. As the East London database has been capturing patient 
Table 5 Relative risk of ESRF/dialysis by ethnic group (competing risks analysis)

\begin{tabular}{|c|c|c|c|c|c|c|}
\hline Variable & $\mathbf{N}$ & ESRF & Per cent & Adjusted HR* & $95 \% \mathrm{Cl}$ & $\mathbf{P}$ values \\
\hline Whole population & 6274 & 224 & 4 & & & \\
\hline White (reference) & 2447 & 57 & 2 & 1 & - & - \\
\hline Indian & 822 & 30 & 4 & 1.24 & (0.63 to 2.43 ) & 0.529 \\
\hline Pakistani & 415 & 10 & 2 & 1.09 & (0.48 to 2.49 ) & 0.843 \\
\hline Black & 1095 & 51 & 5 & 2.23 & (1.25 to 3.98$)$ & 0.007 \\
\hline African & 357 & 19 & 5 & 2.29 & (1.12 to 4.64$)$ & 0.022 \\
\hline Caribbean & 738 & 32 & 4 & 2.20 & (1.14 to 4.27$)$ & 0.019 \\
\hline
\end{tabular}

${ }^{*}$ Model adjusted for age, sex, Townsend deprivation score, HbA1c, BMI, smoking status, eGFR, proteinuria, CVD, ACE/ARB and diabetes duration. All measures except age and gender are time updating.

ARB, angiotensin receptor blocker; BMI, body mass index; CVD, cardiovascular disease; eGFR, estimated glomerular filtration rate; ESRF, end-stage renal failure; $\mathrm{HbA1c}$, glycated haemoglobin.

Table 6 Relative risk of death by ethnic group

\begin{tabular}{|c|c|c|c|c|c|c|}
\hline Variable & $\mathbf{N}$ & Deaths & Per cent & Adjusted HR* & $95 \% \mathrm{Cl}$ & $P$ values \\
\hline White (reference) & 2447 & 461 & 19 & 1.00 & - & - \\
\hline Indian & 822 & 104 & 13 & 0.81 & (0.56 to 1.15$)$ & 0.239 \\
\hline Pakistani & 415 & 42 & 10 & 0.96 & (0.59 to 1.55$)$ & 0.866 \\
\hline Black & 1095 & 139 & 13 & 0.77 & (0.57 to 1.05$)$ & 0.099 \\
\hline African & 357 & 29 & 8 & 0.79 & (0.43 to 1.44$)$ & 0.445 \\
\hline Caribbean & 738 & 110 & 15 & 0.77 & (0.55 to 1.08$)$ & 0.130 \\
\hline
\end{tabular}

*Model adjusted for age, sex, Townsend deprivation score, HbA1c, BMI, smoking status, eGFR, proteinuria, CVD, ACE/ARB, dialysis/ESRF and diabetes duration. All measures except age and gender are time updating.

ARB, angiotensin receptor blocker; BMI, body mass index; CVD, cardiovascular disease; eGFR, estimated glomerular filtration rate; ESRF, end-stage renal failure; $\mathrm{HbA1c}$, glycated haemoglobin.

data since 2006, our study included patients with up to 10 years of follow-up. The median follow-up of 9 years is higher than for database studies of general populations, as individuals with established T2DM tend to be older, and less geographically mobile than younger population groups. The MDRD formula for calculating the eGFR was chosen for this study as it is the standard across primary and secondary cares in the UK, and thus findings using this measure are of relevance to clinicians working in these settings.

\section{Limitations}

As with any observational database study using routinely collected clinical data, some individuals had missing data for the variables of interest, and there will be some coding errors. Missing data may be at random but non-random missing data is possible-related both to patient behaviour and disease severity. ${ }^{25-28}$ Smaller sample sizes in the ethnic subgroups means we may have been underpowered to detect meaningful differences in progression, rapid decline and death. Our inability to capture predictors not available in routine primary care data such as over-the-counter medications, hospital admissions, patient frailty and biomarkers may have resulted in unmeasured residual confounding. For example, regular use of non-steroidal anti-inflammatory drugs is associated with CKD progression. However, due to widespread availability at pharmacies without a prescription, we are unable to accurately quantify exposure to this drug from electronic health records alone. Mortality was identified using patient registration information on the electronic record but was not confirmed using linked Office for National Statistics (ONS) mortality data which may have led to an underestimate of death events. Linkage between electronic health record databases and administrative data has been shown to improve the validity and completeness of coded information. ${ }^{29}{ }^{30}$ Due to small sample sizes in the constituent ethnic subgroups once further stratified by raised blood pressure and proteinuria, it was difficult to discern any clear trends in the average annual decline. 


\section{Implications for practice}

This study has highlighted the importance of measuring proteinuria, and of monitoring and actively managing blood pressure to target among individuals with diabetic CKD. These key aspects of primary care management are well established in the $\mathrm{UK}^{31}$ and up to 2015 were financially incentivised in the Quality and Outcomes Framework, a pay for performance programme across UK primary care ${ }^{32}$ However, the recent national CKD audit in England and Wales has shown that only $54 \%$ of people with diabetes have an annual proteinuria measurement, and that $70 \%$ do not achieve blood pressure target measurements. ${ }^{33}$ Some ethnic groups, particularly Bangladeshi, appear to be more sensitive to the combined effects of proteinuria and hypertension than other ethnic groups. Clinicians need to be aware that younger diabetics $(<55$ years) with CKD are at twice the risk of rapid progression of CKD compared with those $>65$ years and thus need closer monitoring, management of risk factors and early specialist review to delay progression.

Contributors RM, SAH and GD conceived the study. RM extracted the data, conducted the analysis and drafted the initial manuscript. SH drafted the initial manuscript and contributed to revisions. GD and MMY contributed to revisions.

Funding This research received no specific grant from any funding agency in the public, commercial or not-for-profit sectors.

Competing interests None declared.

Patient consent Not required.

Ethics approval Ethical approval was obtained for this observational study (REC reference 09/H1102/71).

Provenance and peer review Not commissioned; externally peer reviewed.

Data sharing statement No additional data are available.

Open Access This is an Open Access article distributed in accordance with the Creative Commons Attribution Non Commercial (CC BY-NC 4.0) license, which permits others to distribute, remix, adapt, build upon this work non-commercially, and license their derivative works on different terms, provided the original work is properly cited and the use is non-commercial. See: http://creativecommons.org/ licenses/by-nc/4.0/

(C) Article author(s) (or their employer(s) unless otherwise stated in the text of the article) 2018. All rights reserved. No commercial use is permitted unless otherwise expressly granted.

\section{REFERENCES}

1. New JP, Middleton RJ, Klebe B, et al. Assessing the prevalence, monitoring and management of chronic kidney disease in patients with diabetes compared with those without diabetes in general practice. Diabet Med 2007;24:364-9.

2. Dreyer G, Hull S, Aitken Z, et al. The effect of ethnicity on the prevalence of diabetes and associated chronic kidney disease. QJM 2009;102:261-9.

3. Lopes AA. End-stage renal disease due to diabetes in racial/ethnic minorities and disadvantaged populations. Ethn Dis 2009;19:47-51.

4. Barbour SJ, Schachter M, Er L, et al. A systematic review of ethnic differences in the rate of renal progression in CKD patients. Nephrol Dial Transplant 2010;25:2422-30.

5. Lewis EF, Claggett B, Parfrey PS, et al. Race and ethnicity influences on cardiovascular and renal events in patients with diabetes mellitus. Am Heart J 2015;170:322-9.

6. Fedewa SA, McClellan WM, Judd S, et al. The association between race and income on risk of mortality in patients with moderate chronic kidney disease. BMC Nephrol 2014;15:136.

7. Dreyer G, Hull S, Mathur R, et al. Progression of chronic kidney disease in a multi-ethnic community cohort of patients with diabetes mellitus. Diabet Med 2013;30:956-63.
8. van den Beukel TO, de Goeij MC, Dekker FW, et al. Differences in progression to ESRD between black and white patients receiving predialysis care in a universal health care system. Clin J Am Soc Nephrol 2013;8:1540-7.

9. Earle KK, Porter KA, Ostberg J, et al. Variation in the progression of diabetic nephropathy according to racial origin. Nephrol Dial Transplant 2001;16:286-90.

10. Ali O, Mohiuddin A, Mathur R, et al. A cohort study on the rate of progression of diabetic chronic kidney disease in different ethnic groups. BMJ Open 2013;3:e001855.

11. Pallayova M, Rayner $\mathrm{H}$, Taheri $\mathrm{S}$, et al. Is there a difference in progression of renal disease between South Asian and white European diabetic adults with moderately reduced kidney function? J Diabetes Complications 2015;29:761-5.

12. Koppiker N, Feehally J, Raymond N, et al. Rate of decline in renal function in Indo-Asians and Whites with diabetic nephropathy. Diabet Med 1998;15:60-5.

13. Parving $\mathrm{HH}$, Lehnert $\mathrm{H}$, Bröchner-Mortensen J, et al. The effect of irbesartan on the development of diabetic nephropathy in patients with type 2 diabetes. N Engl J Med 2001;345:870-8.

14. Marks A, Fluck N, Prescott GJ, et al. Definitions of progression in chronic kidney disease--predictors and relationship to renal replacement therapy in a population cohort with a 6 year follow-up. Nephrol Dial Transplant 2014;29:333-41.

15. Sarnak MJ, Astor BC. Implications of proteinuria: CKD progression and cardiovascular outcomes. Adv Chronic Kidney Dis 2011;18:258-66.

16. nomis official labour market statistics. Census $2011 \mathrm{KS} 201 \mathrm{EW}$ (Ethnic group) - Nomis - Official Labour Market Statistics. https:// www.nomisweb.co.uk/census/2011/ks201ew.

17. EMIS Health. EMIS web: a clinical system for delivering integrated healthcare. https://www.emishealth.com/products/emis-web

18. CEG. The clinical effectiveness group. 2017 http://www.blizard.qmul. ac.uk/ceg-home.html

19. National Institute of Diabetes and Digestive and Kidney Diseases. Estimating Glomerular Filtration Rate (GFR). https://www.niddk.nih. gov/health-information/health-communication-programs/nkdep/labevaluation/gfr/estimating/Pages/estimating.aspx

20. Townsend P. Deprivation. J Soc Policy 1987. https://scholar.go ogle.co.uk/scholar?cluster $=10489544657050089987 \& \mathrm{hl}=$ en\&oi =scholarr\&sa $=$ X\&ved=0CCAQgAMoADAAahUKEwjOxKrA2o_H AhWKiw0KHUdQAsI\#1.

21. Barbour SJ, Er L, Djurdjev O, et al. Differences in progression of CKD and mortality amongst Caucasian, Oriental Asian and South Asian CKD patients. Nephrol Dial Transplant 2010;25:3663-72.

22. Navaneethan SD, Schold JD, Arrigain S, et al. Cause-Specific Deaths in Non-Dialysis-Dependent CKD. J Am Soc Nephrol 2015:26:2512-20.

23. Kovesdy CP, Anderson JE, Derose SF, et al. Outcomes associated with race in males with nondialysis-dependent chronic kidney disease. Clin J Am Soc Nephrol 2009;4:973-8.

24. Wen $\mathrm{CP}$, Matsushita K, Coresh J, et al. Relative risks of chronic kidney disease for mortality and end-stage renal disease across races are similar. Kidney Int 2014;86:819-27.

25. Delaney JA, Moodie EE, Suissa S. Validating the effects of drug treatment on blood pressure in the General Practice Research Database. Pharmacoepidemiol Drug Saf 2008;17:535-45.

26. Delaney JA, Daskalopoulou SS, Brophy JM, et al. Lifestyle variables and the risk of myocardial infarction in the general practice research database. BMC Cardiovasc Disord 2007;7:38.

27. Marston L, Carpenter JR, Walters KR, et al. Smoker, ex-smoker or non-smoker? The validity of routinely recorded smoking status in UK primary care: a cross-sectional study. BMJ Open 2014;4:e004958-7.

28. Test data in general practice are not missing at random-can we identify when they are? Pharmacoepidemiol Drug Saf. Conference, 29th International Conference on Pharmacoepidemiol.

29. Herrett E, Shah AD, Boggon R, et al. Completeness and diagnostic validity of recording acute myocardial infarction events in primary care, hospital care, disease registry, and national mortality records: cohort study. BMJ 2013;346:f2350.

30. Mathur R, Bhaskaran K, Chaturvedi N, et al. Completeness and usability of ethnicity data in UK-based primary care and hospital databases. J Public Health 2014;36:684-92.

31. The National Institute for Health and Care Excellence. Chronic kidney disease | Guidance and guideline topic | NICE. at. https://www.nice. org.uk/guidance/conditions-and-diseases/kidney-conditions/chronickidney-disease.

32. NHS Digital. QOF business rules v33.0. at. http://content.digital.nhs. uk/qofbrv33

33. Nitsch D, Caplin B, Hull SA, et al; National chronic kidney disease audit: national report (part 1), 2017. 